perifèria

Número 13, diciembre 2010

www.periferia.name

\title{
Algo más que un celular: notas sobre el papel de la telefonía móvil en la vida de adolescentes de Santiago (Chile)
}

\author{
Wilson Muñoz Henríquez - Universidad Autónoma de Barcelona ${ }^{1}$
}

\section{Resumen}

A través del estudio de caso de dos adolescentes de Santiago de Chile, se muestra la radical importancia que posee la telefonía móvil en sus vidas. Se destaca el papel que posee esta tecnología como elemento de conexión, pero sobre todo como dispositivo esencial de la identidad personal, mecanismo de inclusión social y potencial fuente de prestigio dentro del grupo de pares.

Palabras claves: Adolescencia, telefonía móvil, identidad, inclusión social, Chile.

\begin{abstract}
This case study of two teenagers in Santiago de Chile shows the radical importance of mobile telephony on their lives. It highlights the role of this technology as connector, but above all as key marker for personal identity, as a mechanism for social inclusion, and as a source of prestige within the peer group.
\end{abstract}

Key words: Adolescence, mobile telephony, identity, social inclusion, Chile.

\section{Introducción}

Durante los últimos años, Chile se ha destacado por poseer unos de lo índices más altos de penetración de la telefonía móvil en Latinoamérica, asociado normalmente al sostenido crecimiento económico desarrollado durante las últimas décadas, el alto nivel de de urbanización y las crecientes relaciones comerciales establecidas con países productores de tecnología (PNUD 2006; ITU 2009; Ureta 2008). En este contexto, mientras inicialmente los primeros teléfonos móviles (que de ahora en

\footnotetext{
${ }^{1}$ Enviar correspondencia a: wilsonsocio@gmail.com
} 


\section{perifèria}

Número 13, diciembre 2010

www.periferia.name

adelante llamaremos también "celulares") pertenecían principalmente a los estratos altos de la sociedad y mayoritariamente a los hombres, en la última década su adquisición comenzó a penetrar rápidamente a gran parte de la población, sobre todo en adultos y jóvenes; aunque también comenzaron a verse en manos de adolescentes, pasando a convertirse rápidamente en un objeto cotidiano en sus vidas. Si bien este ámbito ha sido crecientemente investigado a nivel global, principalmente en países desarrollados (Ling 2000; Fortunati \& Magnanelli 2002; Mante \& Piris 2002; Wilska 2003; Cambell 2005; Harper \& Hamill 2005; Srivastava 2005; Stald 2008), en Chile no existían estudios que profundizaran esta temática, pese a su creciente relevancia. Por ello se llevó a cabo durante los años 2007 y 2009 el estudio "Chile: Cultura Juvenil Móvil en un Contexto Urbano"2, cuyo objetivo general fue investigar la apropiación y uso de las tecnologías móviles de la comunicación que hacen niños y adolescentes en la ciudad de Santiago, y en la cual pude participar activamente.

A partir de la información obtenida durante el desarrollo del trabajo de campo para el caso de adolescentes del estudio mencionado, el presente escrito intenta mostrar concretamente el papel que juegan los teléfonos celulares en la vida adolescente. En términos específicos, se describe el origen de estas tecnologías en sus vidas, algunos de sus principales usos y el rol que juega en la construcción de su identidad, tanto a nivel personal (personalización de la tecnología) como grupal (inclusión y prestigio social). Estos tópicos serán reconstruidos a partir del análisis de la información recogida sobre dos adolescentes: María y Karen. Ambas poseían 16 años durante el desarrollo del trabajo de campo (2008) y cursaban el $3^{\circ}$ medio de un colegio subvencionado católico, ubicado en el centro de Santiago. Ellas formaban parte de un grupo de compañeras de colegio y amigas que se conocían desde pequeñas, siendo María una clara líder de este grupo de 5 chicas, aunque Karen le pisaba los talones en este aspecto. Tanto las entrevistas como

\footnotetext{
2 Este estudio formaba parte del proyecto "Comunicaciones Móviles y Desarrollo Socioeconómico en América Latina", desarrollado durante los años 2007 y 2009, financiado por Fundación Telefónica y dirigido por Dr. Manuel Castells.
} 


\section{perifèria}

Número 13, diciembre 2010

www.periferia.name

observaciones fueron realizadas en las inmediaciones del colegio, gracias a la gestión y mediación de María.

\section{Origen del celular}

Durante las entrevistas, tanto María como Karen fueron capaces de recordar nítidamente el origen de su primer celular, reconstruyendo las características que poseía, los fines y formas mediante las cuales fue adquirido, y destacando la relación estético-afectiva que establecieron con estos objetos. Sea porque haya sido adquirido como una "herencia" de personas mayores (padres o hermanos más grandes) o porque explícitamente se los habrían obsequiado, las adolescentes aseguraron haber insistido en querer obtener su primer teléfono. Sin embargo, Karen recuerda que el celular no fue solicitado por una necesidad meramente funcional, como ella misma relata:

...me lo regaló mi papá, él lo estaba usando y me lo regaló a mi porque se compró uno más nuevo... yo se lo pedí, yo quería tener un celular, porque era la moda, todos los cabros chicos andaban con celular y yo quería tener un celular, mis compañeros ya tenían celular, pero pocos... Me lo dio mi papá, los dos lo decidimos... era pa que se comunicara conmigo... entonces me dijo: 'ahora estai creciendo y te voy a llamar pa saber si querí almorzar y otras cosas' (Karen, 16 años).

Esta presión social por obtener algo a la moda llevó a Karen a realizar sucesivas demandas a sus padres sin mayores procesos de negociación, de manera que a la edad de 10 años obtuvo su primer teléfono móvil heredado. Desde el comienzo este aparato permitió reforzar la relación padre/hija, pues se transformó en un efectivo medio de comunicación, asunto importante pues Karen veía muy poco a su padre desde que se divorció de su madre. Esta adolescente conserva aún este aparato y señaló que era especial, pues no sólo le recordaba mucho a su padre (objetoconector), sino que también se trataba de su primer celular. Karen también entiende que la herencia del celular obedecía a que se encontraba atravesando un proceso vital ("ahora estai creciendo") y que el aparato no sólo simbolizaba este nuevo estatus, sino que además podía ser utilizado para cumplir las necesidades 


\section{perifèria}

Número 13, diciembre 2010

www.periferia.name

que surgen en este nuevo período que se avecinaba: la adolescencia.

A lo largo de las entrevistas, tanto María como Karen mostraron siempre algún tipo de relación afectiva con sus teléfonos celulares. Al recordar sus primeros teléfonos una sonrisa invadía sus caras, expresando gestos de ternura y afirmando que se trataba de objetos preciosos, que fueron algo importante en aquél momento de sus vidas y que les otorgó una cierta distinción entre sus pares.

Sin embargo, con el tiempo estas apreciaciones se transformaron de tal manera que incluso se tornaron antagónicas. El relato de María es claro respecto a cómo puede evolucionar la relación de aprecio estético que había entablado con su celular. Al rememorar las características de su primer celular, señaló:

Era un... [piensa] parecía teléfono inalámbrico, era horrible, era una cuestión ladrillo gigantesco, ni siquiera era un Nokia antiguo, era un Sony Ericsson, horrible, era horrible, me acuerdo que era azul, todos tenían negro y yo tenía azul, yo lo amaba porque era azul, tenía una antena gigante y tenía una pantalla verde partida por la mitad, como que tenía una línea en la mitad y no podíai leer nada, ni siquiera podíai leer la persona que te llamaba, o sea teníai que contestar sí o sí, no tenía pa mensajes, no tenía nada... En ese momento me gustaba, pero me empezó a dar vergüenza, porque ahí empezaron a salir más bonitos, así que después no lo usé más (María, 16 años).

Funcionalidad y estética se fundieron para entablar una relación afectiva con el teléfono celular, sea de aprecio o rechazo. Por un lado, María vivió en carne propia la obsolescencia tecnológica: al no poder enviar mensajes, al no poder ver quién es el remitente de la llamada, etc., su querido y amado celular comenzó a convertirse en algo que "no tenía nada", es decir, comenzó a vaciarse de las propiedades que antes eran valoradas. Es interesante apreciar cómo el objeto aparece como no acabado, es decir, no posee las características que siempre había poseído; no es una cosa constante, pues la apreciación que se tiene de él puede tornarse incluso contraria. En este sentido, pareciera ser la estética la que adquiere más relevancia en esta relación de apreciación, que se torna negativa e incluso burlesca. Esto se aprecia claramente en el uso de la palabra "Iadrillo", pues en Chile se utiliza este

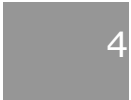




\section{perifèria}

Número 13, diciembre 2010

www.periferia.name

concepto para referirse a los celulares antiguos, señalando con ello que se trata de teléfonos demasiado grandes, cuadrados y pesados, análogo a un ladrillo.

Sin embargo, pese a estas apreciaciones, María continuaba rememorando como un momento especial la llegada de su primer teléfono celular. Además, tanto ella como su amiga Karen conservaban todos sus teléfonos celulares: María los guardaba en un cajón de su cómoda y muchas veces, al mirarlos, recordaba episodios que le sucedieron junto a él. De manera que, pese a tener características negativas (ser feo, horrible, etc.), de todas formas seguía teniendo una carga afectiva positiva y por ello los conservaba, pasando a un segundo plano su funcionalidad técnica.

En este sentido, quizás exista cierta peculiaridad en nuestros casos. En la vida cotidiana, normalmente somos testigos de este tipo de reactivación de las cosas y de sus potentes resignificaciones, transformándose así las relaciones establecidas con los objetos. Sin embargo, es poco común encontrar personas que describan a sus objetos preciados como "horribles", pero que simultáneamente los "amen", valoren y por ello sean conservados. Quizás, ello da cuenta de la complejidad de estos objetos y las relaciones tejidas en su entorno.

\section{Personalización y distinción social: Karen y Matías}

La relación afectivo-estética que estas adolescentes comenzaron a entablar en la preadolescencia con sus aparatos se irá remarcando paulatinamente, acrecentándose con ello los procesos de personalización del teléfono celular y la conformación de su identidad. El celular comienza a convertirse en una necesidad y en un objeto de deseo. En cuanto estos aparatos envejecen y comienzan a poseer menor capacidad de valoración (personal y social), la necesidad de un nuevo aparato llama a la puerta de estas chicas.

Pero a medida que crecen, los padres ya no poseen la misma disposición de compra al respecto, sobre todo porque las demandas se tornan más sofisticadas. Por ello, María y Karen tuvieron que trabajar duro para obtener la suma de dinero necesaria para comprar sus nuevos teléfonos móviles. Estas chicas no son de sectores acomodados, sin embargo el deseo de obtener un nuevo teléfono celular de última 


\section{perifèria}

Número 13, diciembre 2010

www.periferia.name

generación fue más fuerte, como relata Karen:

Quería un celular que fuera nuevo, que tuviera bluetooth, que tuviera cámara, que tuviera de todo... Entonces elegí éste [señala el teléfono celular]... Trabajé en el McDonalds, junté plata y me lo compré...

¿Qué fue lo que más te gustó del celular?

Es que es muy lindo, muy lindo, es como pa mí, es como chiquitito, liviano y, tiene todo poh... Bueno, yo quería primero un celular rosado, una almejita, pero no quedaban, entonces lo que pasa es que yo vi este celular, cuando lo fui a comprar y me dijeron que había llegado hace una semana a Chile, era el nuevo Samsung, el último que había salido, entonces fue como: 'obvio, tengo que comprármelo'.

(Karen, 16 años).

El fenómeno que gatilló la decisión de compra parece claro: era un móvil de última generación, un objeto que ninguno de sus pares tendría y, dada la personalidad de Karen y su particular búsqueda de diferenciación, resultaba "obvio" para ella adquirirlo. Es interesante apreciar cómo desde el primer momento de su compra esta chica se vincula intensamente con este objeto y trata de hacerlo único de diversas formas. Ante la pregunta por la relación que posee con su celular, ella contestó lo siguiente.

¿Te sientes identificada con tu celular?

$\mathrm{Si}$, me siento identificada porque muy, pero muy poca gente lo tiene, nadie conocido mío lo tiene, cachai... Apenas me lo compré, era como 'Oh, Mati', es que lo amo, lo amo... Mi celular es hermoso, es cool, es tierno... tierno porque es como 'cosita' [hace gesto de mimos], como que se abre, como que es chiquitito, es gris, se llama Matías, tiene una estrellita rosada 


\section{perifèria}

Número 13, diciembre 2010

www.periferia.name

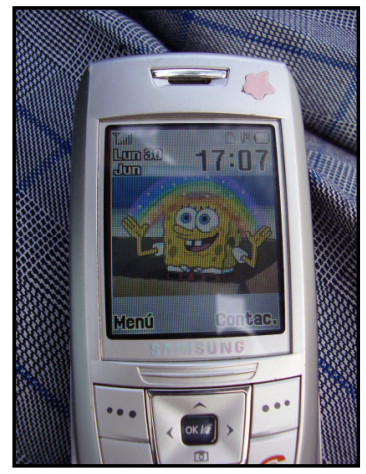

Celular de Karen

Fuente: trabajo de campo

¿Por qué tiene esa estrella?

Porque no me gustaba que fuera tan gris, como muy gris, necesitaba color, así que 'iestrella!' y, mmm, es bacán, es cool... es que mi celular siempre anda en manos de todos, es como 'el celular de la Karen' y me sacan fotos y todo... Me gusta tenerlo enchulado, es que me carga ser igual a todos, me carga, yo siempre tengo que tener una distinción, en lo que sea, ¿cachai?, en todo...

¿Y en este caso cuál es tu distinción?

¿La estrellita?, sí la estrellita rosada, y las fotos que tengo, los colores... son como únicos... Yo soy muy original pa las cosas, trato de que lo que yo tengo nadie mas lo tenga. Eso es primordial para mí. Por ejemplo, este Bob esponja yo sé que nadie lo tiene. Los fondos míos nadie los tiene.

(Karen, 16 años).

Las estrategias manifiestas de Karen para distinguirse entre sus pares son fabulosas. Es interesante cómo inicialmente, al preguntarle si se sentía identificada con el celular, la chica asocia esta idea con el hecho de poseer un objeto único entre sus pares ("nadie conocido mío lo tiene"). En este sentido, ella se siente diferente y única, al igual que su celular. Esto pareciera haber facilitado una vinculación afectiva inmediata con el aparato. El celular pasó a tener vida y personalidad propia, muestra de ello es que ha sido incluso bautizado con un 


\section{perifèria}

Número 13, diciembre 2010

www.periferia.name

nombre propio: Matías. Construido como una extensión de su identidad personal, Matías posee características estéticas y afectivas que lo hacen único. Para Karen pareciera como si realmente estuviera "vivo". Es relevante en este sentido el uso de la palabra "cosita" para referirse a él, pues en Chile suele tener dos acepciones a nivel popular: por un lado, se usa para referirse a seres vivos pequeños, como puede ser una mascota o un bebé, aunque también para referirse a la pareja, teniendo siempre una connotación de ternura; por otro lado, se usa para señalar a una persona que es atractiva sexualmente. Es decir, ambas nos remiten a algo con vida. Además, esto es interesante si consideramos que este aparato es valorado por sus compañeros y suele circular entre ellos, de manera que las peculiaridades del dispositivo permiten ir realizando la identidad social de Karen día a día mediante esta práctica, a partir de su diferenciación con el resto.

Una de las estrategias utilizada frecuentemente por los adolescentes para personalizar sus objetos es "enchular" sus pertenencias. Este término, propio del argot adolescente, refiere a toda intervención que se realiza sobre un objeto para embellecerlo y otorgarle un sello distintivo. En este caso, adosar una calcomanía como la "estrellita rosada" aparece como una práctica hecha de cara al público, pues la adolescente sabe que su celular circula entre sus amigas, de manera que esta estrella rosada indica que se trata de algo exclusivo, no un mero objeto de consumo hecho en serie: se trata de Matías, el Matías de Karen. Esto grafica claramente el nivel de domesticación y personalización del teléfono celular llevado a cabo por Karen.

\section{Nueva conexión: el caso de María}

Cuando realizamos la primera etapa de entrevistas, María había adquirido su nuevo celular hacía sólo 3 semanas y se encontraba totalmente fascinada por él. Sin embargo, su obtención no fue fácil. Ella era consciente de que su madre no podría obsequiarle el teléfono que deseaba. Cuando comentó su decisión de comprárselo a la familia, se negaron en conjunto. La madre señaló que era demasiado caro y peligroso su uso, pues incitaba al robo; mientras que su hermana le dijo que "estaba loca" y simplemente no podía ser. Pero María estaba empecinada en 


\section{perifèria}

Número 13, diciembre 2010

www.periferia.name

comprarse un nuevo celular; el que tenía ya no se ajustaba a ella, e incluso prefería que se lo robaran antes de seguir utilizándolo, según relató.

Ante la negativa de la familia, se ofreció a trabajar durante los dos meses de verano del año 2008 en la panadería de su madre. Increíblemente, este suceso permitió que María y su madre estrecharan sus lazos y se conectaran mucho más. La suya era una de las pocas madres dentro del círculo de amigos y compañeros de colegio que no poseía celular. La adolescente relata que esto le incomodaba, no tanto porque no estuviera al tanto de los avances tecnológicos, sino sobre todo porque generaba una desconexión entre ambas que limitaba su libertad. Muchos de los adolescentes entrevistados se quejaron de que en ocasiones tener un teléfono celular era algo incómodo, pues implicaba llevar siempre con ellos un aparato que permitía que sus padres los ubicaran, los contactaran y potencialmente los controlaran. Sin embargo, María casi "obligó" a su madre a comprarse un teléfono celular, bajo un único fin: poder tener conexión con ella. De esta manera podía establecer un canal cuyo flujo informacional le permitiría tomar decisiones relevantes respecto a asuntos cotidianos.

Pero la conexión no acababa aquí. La madre tenía que aprender a utilizar el teléfono celular, un nuevo reto. Evidentemente, sólo si sabía utilizarlo podría contactarse con María y establecer crecientemente más y nuevas formas de comunicación. Por ello, su hija realizó otra estrategia que las unió ante la tecnología. Nuevamente, sus palabras describen mejor que nadie la situación:

Trabajé y junté la plata pa comprarme el celular, y le dije a mi mamá: 'comprémonos un celular, el mismo pa que yo te enseñe a usarlo y cualquier duda te ayudo, y pa que lo usí realmente... porque si te compras otro, o yo no cacho, penca', ¿cachai? Y nos compramos el celular, iy el más bacán!, onda dijimos que nos dure caleta y la cuestión... Yo le enseñé y le gusta, y anda con el celular pa' arriba y pa' abajo, y lo carga y la wea y me habla de su celular todo el día, eso, bacán... aunque igual le cuesta. (María, 16 años)

Si bien luego de que la madre aprendiera a utilizar el móvil es probable que necesitara en menor medida la ayuda de María, lo interesante es notar cómo 


\section{perifèria}

Número 13, diciembre 2010

www.periferia.name

buscando un fin que aparentemente era práctico y funcional, se generó un espacio de conexión entre madre/hija, gracias a la entrega de conocimiento sobre uso del teléfono celular. Además, si bien es cierto que ambas no compartían el mismo objeto, sus características físicas y funcionales eran casi idénticas. Aquí existe cierta complicidad entre madre e hija que las iguala al tener el mismo teléfono celular, como si existiera una especie de continuidad entre ambas. La valoración positiva que María poseía respecto a su teléfono móvil es extrapolada también a su madre, lo que las hace finalmente a ambas "bacán".

Además de estas nuevas funciones sociales que el nuevo teléfono celular propiciaba, María estaba realmente encantada con él. De hecho, durante las entrevistas hablaba maravillas de su celular, donde aspectos funcionales y estéticos se fundían en este nuevo proceso de domesticación del aparato. De hecho, María señaló sentirse muy identificada con su celular nuevo, argumentando que era muy cómodo, encajaba fácilmente en los bolsillos, era suave, liviano, pertenecía a la marca que le gusta (Sony-Ericsson), era de fácil manipulación, los diseños (en rojo, rosa y plateado) le encantaban, la calidad de imagen de la pantalla también, etc.; en fin, una eterna lista de propiedades. Además, la chica agregó que mientras a sus anteriores celulares le agradaba ponerle adhesivos para adornarlo y distinguirlo del resto de celulares, o incluso le compraba fundas y adornos que se pudieran colgar al móvil ("enchular"), el aprecio por este nuevo teléfono era tal que no necesitaba de ese tipo de personalización, pues en sí mismo ya era único.

María conocía muy bien su nuevo teléfono, pese al poco tiempo que lo poseía cuando la entrevisté. Manejaba fácilmente datos sobre sus diversas funciones, aplicaciones, capacidad de memoria, etc. Esto es interesante si consideramos la variedad de propiedades que hoy en día poseen estos aparatos. Dejemos que María nos presente su querido celular.

Mi celular es rosado [ríe]... ies pechocho! [precioso]. Primero, es la wea más bacán que hay, tiene una imagen muy bacán, porque se ve muy real la imagen y además tiene muchos efectos: onda blanco y negro, tiene como mar, podí sacar 20 fotos por segundo. Eso es lo que me gusta caleta, la cámara, la uso caleta. Los juegos los encuentro muy la raja, onda es una 


\section{perifèria}

Número 13, diciembre 2010

www.periferia.name

tecnología muy bacán... Además es walkman, entonces tiene pa mucha música en verdad, es como un pendrive en verdad, yo tengo un pendrive, pero ya no lo uso porque tengo el celular, porque me cabe más música que en el pendrive y escucho de ahí poh, además se escucha mejor, es muy bacán; y a parte de poder pasarlo al computador, la información al computador por un cable, lo encuentro la raja... me gusta caleta, podí sacar una foto y después la poní en msn... (María 16 años)

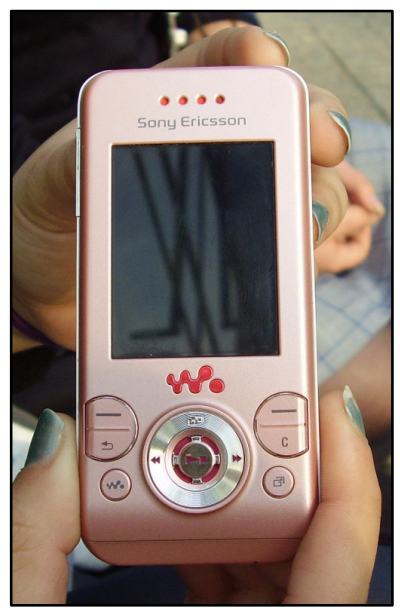

Celular de María

Fuente: foto de campo

Además del conocimiento que posee sobre su objeto y la valoración de sus propiedades, esta cita nos da cuenta de que el celular es un dispositivo que funciona como una especie de "mochila" de otras tecnologías: ella lleva consigo durante todo el día un objeto-dispositivo que le permite realizar llamadas telefónicas, enviar cada vez más mensajes de texto, sacar muchísimas fotos (y de alta calidad), oír música, transportar y pasar información digital, etc. Al realizar todos estos usos, el celular se convierte en un objeto altamente activo. En este sentido, quizás en la actualidad no haya muchos dispositivos que permitan realizar todas estas funciones, que a la vez estén tan cargados de la personalidad y vida social de sus dueños, y que además puedan transportarse tan fácilmente. Quizás estas peculiaridades den cuenta parcialmente de la importancia que posee esta tecnología en la vida adolescente actual. 


\section{perifèria}

Número 13, diciembre 2010

www.periferia.name

Dentro de las múltiples funciones utilizadas, María destacó sobre todo el uso de registros audiovisuales, un elemento distintivo en los celulares de nueva generación. El tener este nuevo celular le evita utilizar cámaras fotográficas cuando sale con sus amigas o si está en clases y necesita inmortalizar momentos determinados.

La cámara es lo que mas me gusta, estoy alucinada con la cámara, me encanta. Lo de los videos y las fotos lo estoy usando caleta, así mandarlo por bluetooh y toda esa cuestión... Los videos los uso entre mis amigos, pa grabar, onda estamos en un carrete y 'ah, grabemos un video', es para grabar momentos, incluso pa momentos familiares... o de repente cantamos canciones, en un carrete pa' grabar los carretes o un cumpleaños, es muy bacán, muy bacán... lo que pasa es que celular la tiene la raja la cámara, entonces después pasai las weas al computador y se ve la raja, no si es muy bacán... de repente estamos en clase y nos ponemos a webiar y decimos 'ya, grabemos a la profe', ya grabemos, riéndonos todo el rato, tirándonos tallas y la cuestión... (María, 16 años).

Como señala la adolescente, la cámara incorporada en su celular no sólo es importante porque tiene una alta calidad de resolución, sino sobre todo por el uso que se le puede dar: sirve para "grabar momentos" especiales y para divertirse. Esta nueva posibilidad de registro, almacenamiento y reproducción de contenidos audiovisuales es realmente una innovación en la vida adolescente, pues al igual que muchos de los adolescentes entrevistados en el estudio, María y Karen no utilizaban o no poseían cámaras para realizar esta función, sin embargo, hoy en día está al alcance de sus manos esta función gracias a sus nuevos celulares.

Es interesante destacar que el celular no sólo sirve para capturar información, sino también para almacenarla, lo que se ve crecientemente posibilitado por las extensiones de la memoria digital. En este sentido, funciona como una especie de (valorado) baúl para María, donde atesora los recuerdos más preciados: videos, fotos y mensajes que no quiere olvidar y que son especiales para ella. Por ejemplo, María me mostró una foto que se hicieron hace algún tiempo en un mall comercial 


\section{perifèria}

Número 13, diciembre 2010

www.periferia.name

de Santiago (Mall Plaza Vespucio) con su amiga Karen. En este lugar, los fines de semana por las tardes suelen reunirse muchos adolescentes, sobre todo pertenecientes a las popularmente denominadas "tribus urbanas". María recuerda que guarda esta foto donde salen ambas con unas sonrisas de cartón (caretas), tanto porque encuentra que es una imagen graciosa y original, como por lo que pasó aquél día. En la foto ambas salen muy alegres y unidas. Recuerdo que María me dijo sonriendo: "Habían razones para estar alegres". Fue un momento especial y el motivo de la alegría no fue revelado en aquélla entrevista, aunque vivirá en el teléfono celular y claramente en sus recuerdos.

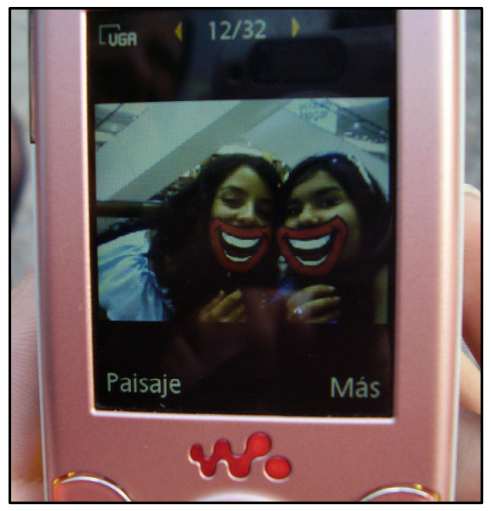

Foto en el celular de María

Fuente: Foto de campo

Así, mensajes, vídeos y fotografías adquieren importancia como objetos preciados y que conectan de manera importante a las personas. En este caso se trata no sólo de recordar a su amiga y tenerla presente, o de recordar lo gracioso que fue ponerse aquellas caretas, sino también rememorar un suceso que en principio escapa a la fotografía misma, pero que es evocado por ella: el secreto de lo que ocurrió aquella tarde en un mall de Santiago.

Por último, es importante comprender las múltiples y emergentes posibilidades de personalización que abren las nuevas funcionalidades de la telefonía móvil. Como ha señalado María, ya no se trata meramente de cuestiones externas y/o estéticas del celular. Por ejemplo, dentro de su móvil María tiene muchos contactos telefónicos - sobre todo de las personas más queridas, como la familia, la pareja o 


\section{perifèria}

Número 13, diciembre 2010

www.periferia.name

las amigas - personalizadas con sus fotos preferidas, la música que les gusta o con un ringtone que los caracteriza. De esta forma, una simple llamada de un amigo permite evocarlo tanto a nivel visual como sonoro, diferenciándolo del resto. Es como si llevara de manera permanente a todo su mundo social en su celular, reproduciendo sus diferencias gracias a las posibilidades que abre esta tecnología.

Un ejemplo concreto es el uso de ringtones. María señala que cuando llama su amiga Karen, suena la canción preferida de su amiga, un tema romántico que ambas conocen de su grupo musical favorito ("Aleste"), mientras que cuando llama su madre o su hermana mayor suena una melodía que es el tema principal de la popular película "El exorcista". A María le hace gracia cuando llama su novio, pues suena la frase: "iWeona, andai puro maraqueando!". En Chile, maraquear es un modismo que viene de maraca, que popularmente significa prostituta. Sin embargo, a ella pareciera hacerle gracia esta frase, pues señala que ambos encuentran inconcebible e insólito que algunas personas la utilicen. En cierta forma, lo usan como una burla jocosa, pero que sólo está permitida con su novio, diferenciándolo así del resto de contactos.

\section{Lucha por el prestigio}

La adquisición de su nuevo celular por parte de María, tuvo impactos diferenciados según los ámbitos sociales que frecuentara. Mientras en la familia fue inicialmente criticada, en el colegio y dentro del grupo de amigas ocurrió algo extraordinariamente interesante y que permite entender la importancia que poseen estos aparatos para la vida personal y social de estas chicas.

Como señalábamos al principio, dentro del grupo de amigas María es claramente la líder, aunque Karen parece ser la segunda a bordo al respecto, de manera que las decisiones de ambas marcan una pauta importante en el grupo. Este contexto grupal es necesario tenerlo en consideración, pues en él se inserta la adquisición de nuevas tecnologías y las relaciones sociales que se tejen a su alrededor. La búsqueda de inclusión y prestigio por parte de María y Karen a través de la tecnología, ha sido clave en el grupo a la hora de utilizar teléfonos celulares. De hecho, la adquisición del teléfono de María reconfiguró este escenario socio-técnico 


\section{perifèria}

Número 13, diciembre 2010

www.periferia.name

establecido entre humanos y no-humanos, generando ciertas tensiones entre estas amigas.

Como vimos, antes de la llegada del teléfono celular de María, Karen y Matías eran los protagonistas de la función, sobre todo dentro del colegio. Ambas chicas nos relataron que Matías ya era conocido por todos los compañeros, quienes inmediatamente identificaban que se trataba del celular de Karen. Solicitado para sacar "mejores" fotos, escuchar "más" música, jugar con videojuegos que otros teléfonos no poseían, etc.; Matías circulaba dentro del grupo de curso con naturalidad y Karen estaba feliz con este hecho. Hasta que María se compró su nuevo teléfono. ¿Qué sucedió entonces? No sin pesar, Karen nos relata la situación.

¿Cómo cambió la situación cuando llegó el celular de la María?

Es que es más moderno el de la María, es rosadito, tiene luces, entonces es como 'ah, qué lindo tu celular', y el mío es como... [hace muecas y pone una cara triste] como que pasó a segundo plano... el mío era el que tenía más uso, pero ahora apareció el de la María y me robó protagonismo... Pero el mío era el más moderno entre las tres [amigas], después se compró la María el suyo y me cagó...

¿Pero eso sólo pasó en su grupo de amigas?

No, también en el curso, si el de la María es el más moderno... Antes con el mío era como: 'Oh, ¿cuánto te costó?, ¿cómo es?', o 'es bacán, quiero uno' y la wea... Y ahora: 'Qué lindo María tu celular' y 'Karen: no existes'

(Karen, 16 años)

El relato de Karen habla por sí solo. La vinculación que existe entre las funcionalidades, la estética del celular y su dueña es clara. María ha llegado a este nuevo escenario con el celular más "moderno" del grupo de amigas y del curso, arrebatándole esta categoría que poseía Matías anteriormente ("era el más moderno entre las tres") y con ello también perdiendo protagonismo Karen, pasando ambos literalmente a "segundo plano", o usando una expresión más fuerte 


\section{perifèria}

Número 13, diciembre 2010

www.periferia.name

y que denota cierta intencionalidad en la acción, Karen señala: "me cagó". Es interesante cómo Karen sella el relato, pues mientras antes ella y su móvil eran el centro de atención entre los adolescentes, ante este nuevo fenómeno la desatención de los chicos hacia ella y su celular indirectamente le dicen: "Karen: no existes", es decir, no existe Matías y por ende tampoco Karen, una asociación directa entre objeto-persona muy relevante para comprender el papel que juegan estos dispositivos en la vida de estas chicas.

Pero veamos el otro lado de la moneda, nuestros nuevos protagonistas: María y su celular nuevo, y lo que significó para ambos aparecer en escena aquél primer día en el liceo. María recuerda claramente aquél episodio, tanto porque había sido reciente como por la importancia de lo sucedido.

El primer día que lo traje al liceo, le puse como poca batería a propósito, porque o si no me lo iban a quitar todo el día, porque todos andaban: 'ioh! déjame ver tu celular', y era como: 'ila María tiene un celular muy bacán!', porque tiene de todo, si de verdad que es muy bacán mi celular, y andaba todo mi curso alucinado... y me lo quitaban y todo [ríe], decían qué bonito, y cosas así... era como 'qué bacán, muéstrame todo lo que hace', yo les tenía que estar mostrando las weas, y al final quedaban alucinadas... De repente un compañero me dijo: 'sácame una foto tú, con tú celular, porque los demás no se ven tan bien como el tuyo', ¿cachai?... La otra vez se lo mostré a mis primos, iy me lo quitaron!, me decían: 'no, déjame sacarme fotos y la cuestión', cachai, ilo amaron!

¿Te sientes identificada con él?

Sí, mucho [en ese momento, interrumpe la entrevista una de sus amigas y relata: "es como 'el celular de la María', es como ¿cachaste el celular de la María?, o 'me voy a comprar el celular de la María', es como un tipo de celular, todavía es así, muchos le dicen: 'oh María, me quiero comprar tu celular"] 


\section{perifèria}

Número 13, diciembre 2010

www.periferia.name

La obtención del nuevo celular de parte de María fue todo un suceso. Aunque incomprendida por sus familiares, sus compañeros de curso quedaron simplemente deslumbrados ante el nuevo objeto. María no desconocía el impacto que tendría el móvil entre sus compañeros (muestra de ello es que descarga la batería porque sería muy solicitado). Especie de objeto mágico, todos sus compañeros querían poder manipularlo, aprender a usarlo y rápidamente se transformó en un referente. Esto se grafica de manera clara en la petición de uno de sus compañeros: "sácame una foto tú, con tú celular", señalando con ello que se trataba de un objeto único. María identifica una situación similar con sus primos. Pareciera realmente como si se tratara de un objeto extremadamente especial, que merece la adoración de todos y, de esta forma, se comienza a tejer una relación en torno al celular y María.

Es interesante ver cómo esto contribuye al proceso de construcción de la identidad de la adolescente y cómo la posiciona entre sus compañeros de curso. Como señala claramente su amiga, el nuevo objeto obtenido no es simplemente un objeto de mercado, sino que "es como un tipo de celular", es decir, la identidad de María está totalmente fundida en este aparato para muchos de sus compañeros. Ya no se trata ni siquiera de una simple representación de ella, sino que es una especie de fascinante extensión de la propia adolescente.

Sin embargo, un objeto con estas características y con la importante vinculación que posee con la identidad personal, no podía dejar incólume a las antecedentes relaciones de prestigio entabladas en torno a la tecnología dentro del grupo. Como en todo ámbito socio-técnico, el ascenso y notoriedad de un actor y sus objetos puede reconfigurar la distribución de prestigio; por ello, muchos no estaban tan alegres como María con este nuevo celular. $Y$ esto se hizo notar desde el primer día.

¿Esperabas que tus compañeros reaccionaran así el primer día que llevaste tu celular?

iSi poh!, igual era como el juguetito nuevo... lo que me molestó es que igual había gente con envidia... Entre mis amigas igual fue como: 'ah, sí' [pone cara de seria e indiferente]... el curso era 'hay que lindo, déjame verlo', y las otras 


\section{perifèria}

Número 13, diciembre 2010

www.periferia.name

[amigas] eran como: 'ah, la wea'... Lo que pasa es que tengo una amiga que quería un celular rosado todo el rato, de mi grupo, muy cercana, la Karen... ipero no le digai!, pero como yo me compré el celular rosado, fue como: 'iah, ya, el tuyo es rosado!', y me tiró mierda y la wea, pero nada, yo dije: '¿Sí?, qué pena' (María, 16 años).

Si bien los compañeros del curso manifestaron directamente el agrado ante la compra del celular, María advierte que la recepción de parte del grupo de amigas, y más específicamente de Karen, no fue la esperada. Debemos recordar aquí la personalidad que posee Karen y la importancia que le otorga al hecho de poder distinguirse dentro del grupo, sobre todo gracias al uso de su celular. Ella había manifestado su intención de tener un móvil rosado (del mismo color de su estrella y de muchos accesorios que posee). Según relata María, esta amiga directamente la increpa ("me tiró mierda") por algo que entendió como una especie de copia o traición.

Pero más allá de si esto ocurrió exactamente así, lo que queda claro es la "actividad" que poseen estos objetos, donde se muestra que las cosas son más que meras existencias e incluso pueden tensar relaciones. Es interesante la lucha que se crea con el celular nuevo, pues se abre un abismo entre estas amigas. En este sentido, vemos que el celular no es meramente un objeto: lo que se ha visto desplazado es Matías, aquel objeto cuasi-vivo de Karen y que le permitía una forma de socialización entre sus compañeros. Alguien podría objetar que el celular es secundario en este fenómeno, y que sobre todo importan las relaciones sociales de prestigio pre-existentes; pero habría que preguntarse si esta situación hubiese ocurrido si el celular de María hubiese sido de color gris o menos sofisticado. La experiencia etnográfica nos muestra más bien que para estas adolescentes la objetualidad y materialidad de sus celulares sí importa, y mucho.

\section{Conclusiones}

A lo largo de este breve escrito he querido mostrar la radical importancia que poseen estos nuevos dispositivos en la vida adolescente. Esto se aprecia desde su primera llegada, construida previamente en base a expectativas asociadas 


\section{perifèria}

Número 13, diciembre 2010

www.periferia.name

claramente a la inclusión en el grupo de pares gracias a la obtención de esta tecnología. Además, el suceso es rememorado afectivamente como un verdadero mito de origen, dando cuenta de la importancia del episodio. Que ambas chicas (así como muchos otros adolescentes entrevistados) conserven su primer celular es también una muestra más de ello. Por otra parte, a medida que estas chicas fueron creciendo, el celular no sólo permitió ir tejiendo importantes relaciones sociales, como las que existe entre padre/hija en Karen o madre/hija en María; sino que sobre todo se fue convirtiendo en una verdadera extensión de su identidad, tanto a nivel personal como grupal, de manera que sufrió las transformaciones asociadas a esta edad. En este sentido, la relación que María y Karen establecieron con estos objetos no fue simplemente entre "personas" y "cosas" sin más, pues la actividad que estos dispositivos generan y en la que están involucrados es impresionante, al punto de que estas tecnologías pueden adquirir nombres propios (como "Matías") y pueden ser tratados incluso como cosas vivientes ("cosita"). Finalmente, quizás la lucha entablada en torno al desplazamiento de Matías y Karen debido al advenimiento del nuevo celular de María, y su nuevo liderazgo y prestigio asociado, da cuenta de este hecho: los celulares no sólo son de personas específicas, o relacionan a personas, sino que muchas veces parecieran ser realmente extensiones materiales de ellas mismas; pues en y a través de estos dispositivos se juega también su identidad personal y social cotidianamente. Y quizá hoy en día más que nunca gracias el cambio de naturaleza de la información, posibilitado por la emergencia del registro audiovisual, y en un entorno que crecientemente se auto-comprende como parte de una sociedad de la información.

\section{Bibliografía}

Cambell, Marilyn (2005). "The impact of the mobile phone on young people's social life". Social Change in the 21st Century Conference, Centre for Social Change Research Queensland University of Technology, October.

Fortunati, Leopoldina y Magnanelli, Anna (2002). "El teléfono móvil de los jóvenes". Revista de Estudios de Juventud, 57, pp. 59-78.

Harper, Richard and Hamill, Lynne (2005). "Kids will be Kids: The Role of Mobiles in 


\section{revista de recerca i formació en antropologia}

\section{perifèria}

Número 13, diciembre 2010

www.periferia.name

Teenage Life", in Hamill, L. and Lasen, A. (eds). Mobile World: Past, Present and Future. Springer-Verlag, pp. 61-74.

ITU (2009). Information Society Statistical Profiles 2009 - Americas. Geneva: International Telecommunications Union.

Ling, Rich (2000). "The adoption of mobile telephony among Norwegian teens". Telenor notat, 57.

Mante, Enid y Piris, Dóris (2002). "El uso de la mensajería móvil por los jóvenes en Holanda". Revista Estudios de Juventud, 57 (2), pp. 47-58.

PNUD (2006). Informe de Desarrollo Humano en Chile 2006. Las Nuevas Tecnologías: ¿un salto al futuro? Santiago de Chile: Programa de las Naciones Unidas para el Desarrollo.

Srivastava, Lara (2005). "Mobile phones and the evolution of social behaviour". Behaviour \& Information Technology, 24 (2), pp. 111 - 129.

Stald, Gitte (2008). "Mobile Identity: Youth, Identity, and Mobile Communication Media", in D. Buckingham (ed.). Youth, Identity, and Digital Media. Cambridge: MIT Press, pp. 143-164.

Ureta, Sebastián (2008). "Mobilising poverty? Mobile phone use and everyday spatial mobility among low income families in Santiago, Chile". The Information Society, 24 (2), pp. 83-92.

Wilska, Their-Anna (2003). "Mobile Phone Use as Part of Young People's Consumption Styles". Journal of Consumer Policy, 26, pp. 441-463. 